\title{
Relationship between structure and function of dietary fibre: a comparative study of the effects of three galactomannans on cholesterol metabolism in the rat
}

\author{
BY A. J. EVANS, R. L. HOOD, D. G. OAKENFULL AND G. S. SIDHU \\ CSIRO Division of Food Processing, Food Research Laboratory, PO Box 52, North Ryde, \\ NSW 2113, Australia
}

(Received 18 October 1990-Accepted 1 August 1991)

\begin{abstract}
Male adult rats were fed on diets containing $80 \mathrm{~g} / \mathrm{kg}$ galactomannans with different galactose $(G)$ : mannose (M) ratios/kg. The galactomannans were compared with purified cellulose (Solkaflok) and the animals were also fed on a basal diet free from fibre. All diets contained cholesterol $(10 \mathrm{~g} / \mathrm{kg})$ and sodium cholate $(2 \mathrm{~g} / \mathrm{kg})$. The three galactomannans were fenugreek gum $(1 \mathrm{G}: 1 \mathrm{M})$, guar gum $(1 \mathrm{G}: 2 \mathrm{M})$ and locust-bean gum $(1 \mathrm{G}: 4 \mathrm{M})$. In comparison with the fibre-free and Solkaflok diets, all three galactomannans lowered the concentrations of cholesterol in both liver and blood plasma. The galactomannans also decreased the rate of hepatic synthesis of cholesterol. Dietary galactomannans increased caecal volatile fatty acids, particularly propionic, increased the weight of the caecum and its contents and increased the amount of water in the faeces. The increase in propionic acid production was significantly related to a decrease in caecal $\mathrm{pH}$, but not to changes in plasma cholesterol or hepatic cholesterol synthesis. These effects were significantly influenced by chemical composition and structure of the galactomannan; they were most evident when the proportion of galactose in the galactomannan was highest (i.e. fenugreek gum). The three galactomannans also differed markedly in their effects on the viscosity of the digesta, but the galactomannan which gave the highest viscosity was least effective in lowering plasma cholesterol. A separate experiment with perfused loops of small intestine in vivo showed that the most effective galactomannan, fenugreek gum, had no direct effect on cholesterol absorption.
\end{abstract}

Galactomannans: Dietary fibre: Cholesterol: Rat

The only forms of dietary fibre which have been convincingly shown to have the ability to lower plasma cholesterol concentrations are water-soluble fibre fractions. Pectins have been shown to lower plasma cholesterol in animal experiments and in human trials (Judd \& Truswell, 1982, 1985). Similarly, guar gum has been shown to be effective in both animal and human studies (Jenkins et al. 1975, 1980; Simons et al. 1982). Xanthan gum (Osilesi et al. 1985), gum acacia (Sharma, 1985), locust-bean gum (Zavoral et al. 1983) and karaya gum (Behal et al. 1984) can also be effective, and the ability of oat bran to lower plasma cholesterol (Kirby et al. 1981) appears to be due to its high level of water soluble $\beta$-glucans (Chen et al. 1981; Oakenfull, 1988).

The ability of soluble fibre to lower plasma cholesterol concentrations appears to be due to either or both of two possible causes. First soluble fibre increases the viscosity of the digesta and increases the thickness of the unstirred layer in the small intestine. It might, therefore, be expected to inhibit uptake of cholesterol and bile acids (Gee et al. 1983). Secondly, having passed through the small intestine, soluble fibre is an excellent substrate for fermentation by the micro-organisms in the large bowel. The volatile fatty acids produced by fermentation enter the blood stream and appear to suppress hepatic cholesterol synthesis (Anderson \& Bridges, 1981). 
(a)

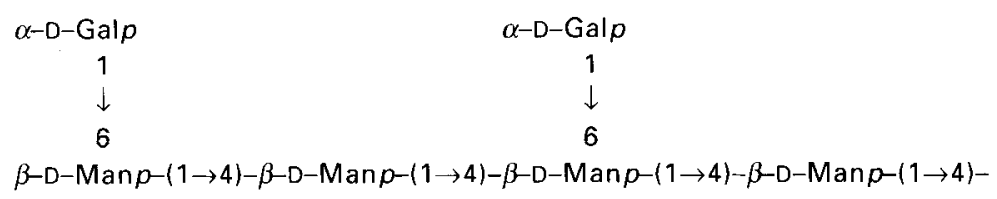

(b)

$\alpha-\mathrm{D}-\mathrm{Gal} p$<smiles>[B]I</smiles>

$\beta-D-M a n p-(1 \rightarrow 4)-\beta-D-M a n p-\{1 \rightarrow 4)-\beta-D-M a n p-(1 \rightarrow 4)-\beta-D-M a n p-(1 \rightarrow 4)-$

Fig. 1. Schematic diagram of the structure of the repeat unit of $(a)$ guar (Cyamopsis tetragonolohus) gum and (b) locust bean (Ceratonia siliqua) gum.

A comparison of a series of galactomannans offers the opportunity to examine further these mechanistic possibilities and at the same time to investigate how small changes in the chemical structure of the polysaccharide might influence its metabolic effect.

The three galactomannans chosen were guar gum, locust-bean gum and fenugreek gum, all derived from the endosperm of seeds of Leguminosae species. Structurally they are based on a $\beta$-D-( $1 \rightarrow 4)$-linked backbone of $\beta$-D-mannopyranosyl residues with side chains of single $\alpha$-D-galactopyranosyl groups linked $\alpha$-D- $(1 \rightarrow 6)$, as shown in Fig. 1 (Dea \& Morrison, 1975). Depending on the botanical source, the galactomannans can have a range of galactose $(\mathrm{G})$ : mannose $(\mathrm{M})$ ratios. For fenugreek gum (Trigonella foenum-graecum) the ratio is approximately $\mathrm{IG}: 1 \mathrm{M}$, for guar gum (Cyamopsis tetragonolobus) approximately $1 \mathrm{G}: 2 \mathrm{M}$ and for locust-bean gum (Ceratonia siliqua) approximately $1 \mathrm{G}: 4 \mathrm{M}$.

When included in the diets of cholesterol-fed rats, all three gums lowered plasma cholesterol compared with a control diet based on purified cellulose. More interestingly, the chemical structure influenced the magnitude of the effect.

\section{MATERIALS AND METHODS}

Animals and diets

Adult male Wistar rats (200-230 g body-weight) were used. They were randomly assigned to each diet group, six per group, and were housed in groups of three in cages with wiremesh bottoms to minimize coprophagy. They were kept in a constant temperature environment $\left(25 \pm 1^{\circ}\right)$ with a $12 \mathrm{~h}$ cycle of light and dark. They were given free access to water and to the appropriate diet listed in Table 1 for a period of 2 weeks. The basal diet contained no dietary fibre.

\section{Analytical procedures}

Fresh faecal pellets (two per rat) were collected for moisture analysis on the last day of the treatment period. The animals were anaesthetized in an atmosphere of carbon dioxide. Blood was collected directly from the heart, and the liver and caecum were removed and weighed. The caecal contents were extruded from the caecum and thoroughly mixed with four parts of deionized water for measurement of caecal $\mathrm{pH}$. To $1 \mathrm{ml}$ of this suspension was added $0.1 \mathrm{ml}$ sulphuric acid $(500 \mathrm{ml} / \mathrm{l})$ and the supernatant fraction after centrifugation was used for measurement of volatile fatty acids. These were measured with a Perkin-Elmer Sigma 3B gas-liquid chromatograph fitted with a glass column (length 2 m; i.d. $2 \mathrm{~mm}$ ) 
Table 1. Composition of the diets $(\mathrm{g} / \mathrm{kg})$

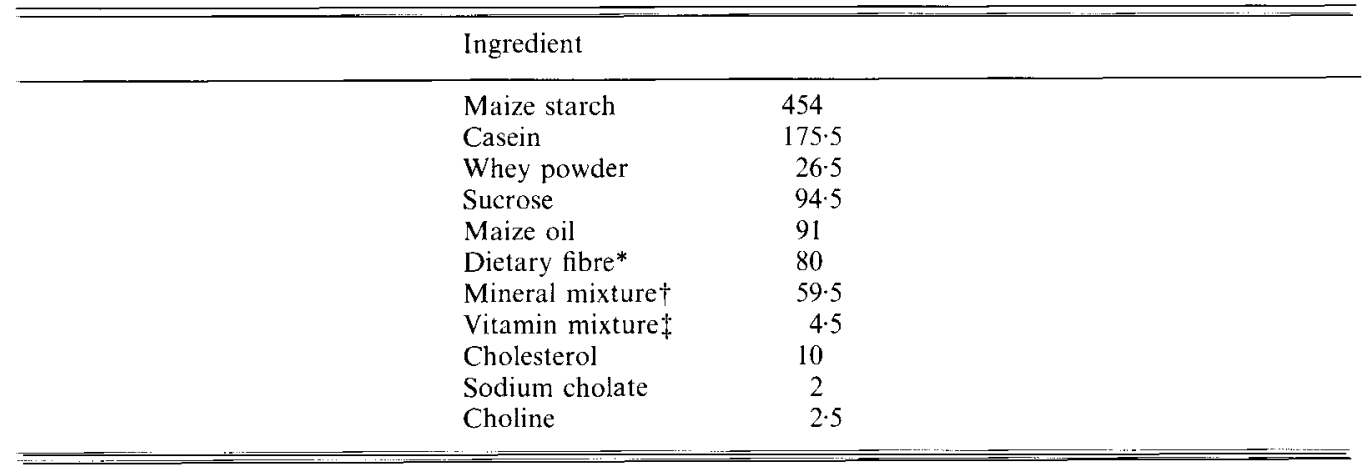

* Either guar (Cyamopsis tetragonolobus) gum, locust-bean (Ceratonia siliqua) gum, fenugreek (Trigonella foenum-graecum) gum or Solkaflok (a purified, non-fermentable fibre).

+ Mineral content $(\mathrm{g} / \mathrm{kg})$ : calcium carbonate 46 , potassium dihydrogen phosphate 8 , iodized sodium choride 3.5 , magnesium sulphate 1 , ferric ammonium citrate $0 \cdot 7$, manganese acetate $200 \mathrm{mg}$, zinc sulphate $60 \mathrm{mg}$, copper acetate $20 \mathrm{mg}$, ammonium molybdate $6 \mathrm{mg}$, chromium acetate $5 \mathrm{mg}$, sodium selenate $0.1 \mathrm{mg}$.

$\ddagger$ Vitamin content $(\mathrm{mg} / \mathrm{kg})$ : riboflavin 9 , thiamin 6 , pyridoxine $1 \cdot 5$, ascorbic acid 475 , nicotinamide 79 , sodium pantothenate 3.75 , vitamin D 4500 I.U., vitamin A 18000 I.U.

packed with Chromosorb 101 and operated isothermally at $170^{\circ}$. Total plasma and highdensity-lipoprotein (HDL)-cholesterol were measured using enzymic kits (BoehringerMannheim). Liver lipids were isolated using the extraction method of Bligh \& Dyer (1959) and cholesterol measured in the non-saponifiable fraction using the methods of Hood (1987) and Rudel \& Morris (1973). Thin slices of liver (100-150 mg) were incubated in $20 \mathrm{ml}$ vials containing $3 \mathrm{ml}$ Krebs-Ringer buffer $\left(\mathrm{Ca}^{++}\right.$-free) as described by Hood (1990).

\section{Viscometry}

The rheological properties of aqueous solutions of the three galactomannans were studied using a Bohlin VOR Rheometer with cone and plate geometry. All measurements were made at $37^{\circ}$. Measurements were made of the variation of apparent viscosity with shear rates within the range $0.02-15 / \mathrm{s}$.

\section{Absorption from loops of small intestine}

The animals were male Wistar rats of body-weight 200-250 g maintained on a commercial diet containing $230 \mathrm{~g}$ protein $/ \mathrm{kg}$ and $50 \mathrm{~g}$ crude fat $/ \mathrm{kg}$ (Allied Feeds, Rhodes, NSW). They were starved of food overnight and anaesthetized with intraperitoneal sodium pentobarbital $(60 \mathrm{mg} / \mathrm{kg}$ body-weight). The abdomen was opened by midline incision and the entire length of the jejunum and ileum divided into two sections, 'upper' and 'lower', of approximately equal length. Inflow cannulas were fitted and the lumen of each section was washed with isotonic saline $(9 \mathrm{~g}$ sodium chloride $/ 1)$ at $37^{\circ}$. Outflow cannulas were then fitted and the sections replaced inside the abdominal cavity which was closed using surgical clips. Isotonic solutions, $\mathrm{pH} 7.4$ at $37^{\circ}$, were circulated separately through the lumen of each section at $2 \mathrm{ml} / \mathrm{min}$ for $60 \mathrm{~min}$. The solution for the upper loop initially contained either ${ }^{3} \mathrm{H}$-labelled glucose $(10 \mathrm{~mm})$ or a micellar solution of ${ }^{3} \mathrm{H}$-labelled cholesterol $(0.1 \mathrm{~mm})$ with sodium taurocholate $(10.0 \mathrm{~mm})$, oleic acid $(1.2 \mathrm{~mm})$ and monoolein $(0.6 \mathrm{~mm})$. The solution for the lower loop initially contained ${ }^{3} \mathrm{H}$-labelled glucose $(10 \mathrm{~mm})$ or ${ }^{3} \mathrm{H}$-labelled sodium taurocholate $(4 \mathrm{mM})$. All solutions also contained ${ }^{14} \mathrm{C}$-labelled $\mathrm{CrEDTA}$ to monitor absorption or loss of water. Samples of the circulating solution were taken at 20 min 


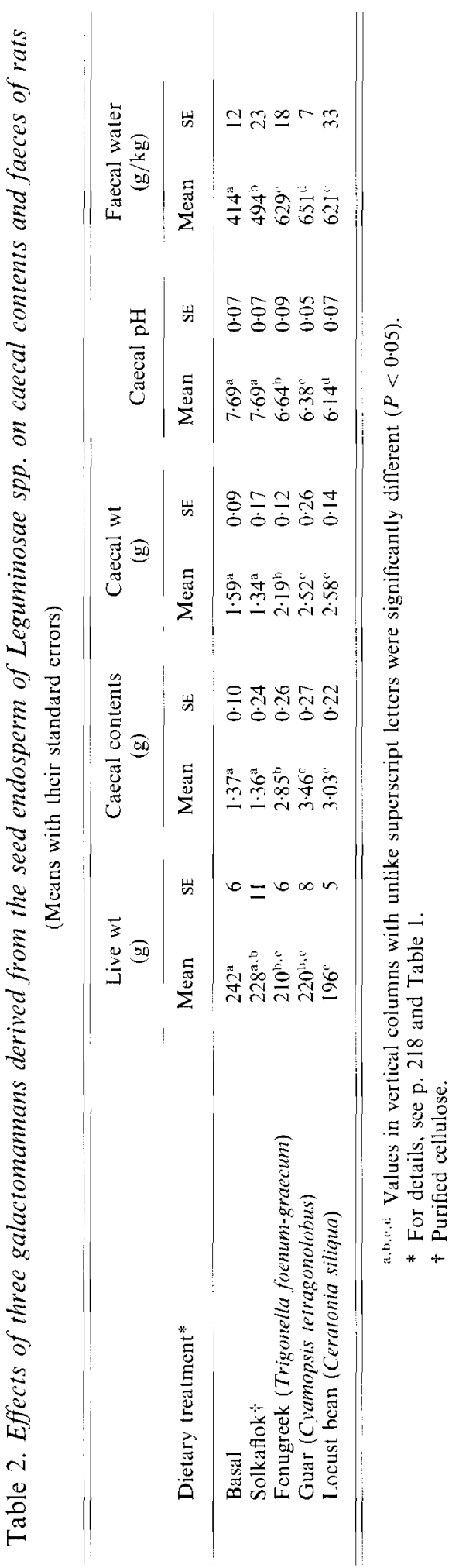


intervals for radioactive counting. Rates of absorption of cholesterol, taurocholate and glucose were calculated with appropriate corrections for water flux.

\section{Statistical analyses}

Differences between means were tested using a two-sided $t$ test, taking $P<0.05$ as the criterion of significance. Relationships between variables were examined using correlation coefficients between pairs (Snedecor \& Cochran, 1989) calculated using MINITAB.

\section{RESULTS}

Effects on the body-weight, caecum and faeces

The average weights of the rats were similar for each group at the commencement of the dietary treatment. At the end of the 2 -week treatment weight gains and final body-weights (Table 2) were similar for the three groups given galactomannan, intermediate for rats given Solkaflok and highest for rats on the basal diet. Feeding the galactomannans caused large increases in the weight of the contents of the caecum and also in the weight of the caecum after the contents had been expressed (Table 2).

The $\mathrm{pH}$ of the caecal contents was lower for the galactomannan-fed animals than for those fed on the basal diet or Solkaflok, indicating more intensive microbial activity with production of volatile fatty acids.

The galactomannans all increased the water content of the faeces compared with the basal diet or Solkaflok. The differences between the individual galactomannans were small, however, and not statistically significant.

\section{Liver and plasma cholesterol concentrations}

The results presented in Table 3 show that the galactomannans strongly influenced the levels of cholesterol in liver and plasma. In each case the levels were considerably lower than when the animals were fed on the basal (fibre-free) diet or Solkaflok. In addition, there were smaller but mostly significant differences between the galactomannans. The higher the density of galactose side chains the greater the effect. Thus, the magnitude of the cholesterol-lowering effect was consistently in the order fenugreek $>$ guar $>$ locust bean.

The only difference observed between the fibre-free and Solkaflok diets was in the small increase in the total plasma cholesterol, particularly the non-HDL component, in response to dietary Solkaflok.

\section{Rates of cholesterol synthesis}

Rates of cholesterol synthesis were estimated in the liver and small intestine from $\left[{ }^{14} \mathrm{C}\right]$ mevalonate (Hood, 1990). These results are shown in Table 4 . The galactomannans had a dramatic effect on hepatic cholesterol synthesis which was lowered by a factor of approximately two when compared with the basal and Solkaflok diets. Again there were smaller but significant differences between the effects of the individual galactomannans. The magnitude of inhibition of cholesterol synthesis was in the same order as the lowering of plasma and liver cholesterol: fenugreek $>$ guar $>$ locust bean.

\section{Caecal volatile fatty acids}

Acetic, propionic and butyric acids were the major fermentation products in the caecum of rats fed on either the basal or Solkaflok diets (Table 5). When galactomannan replaced Solkaflok in the diet the proportions of the different volatile fatty acids were altered; in particular, propionic acid increased and butyric acid was detected only in trace amounts. Propionate production was greatest when the rats were fed on locust-bean gum which had the least number of galactose side chains. The effects of diet on the proportions of the volatile fatty acids are shown in Fig. 2. 


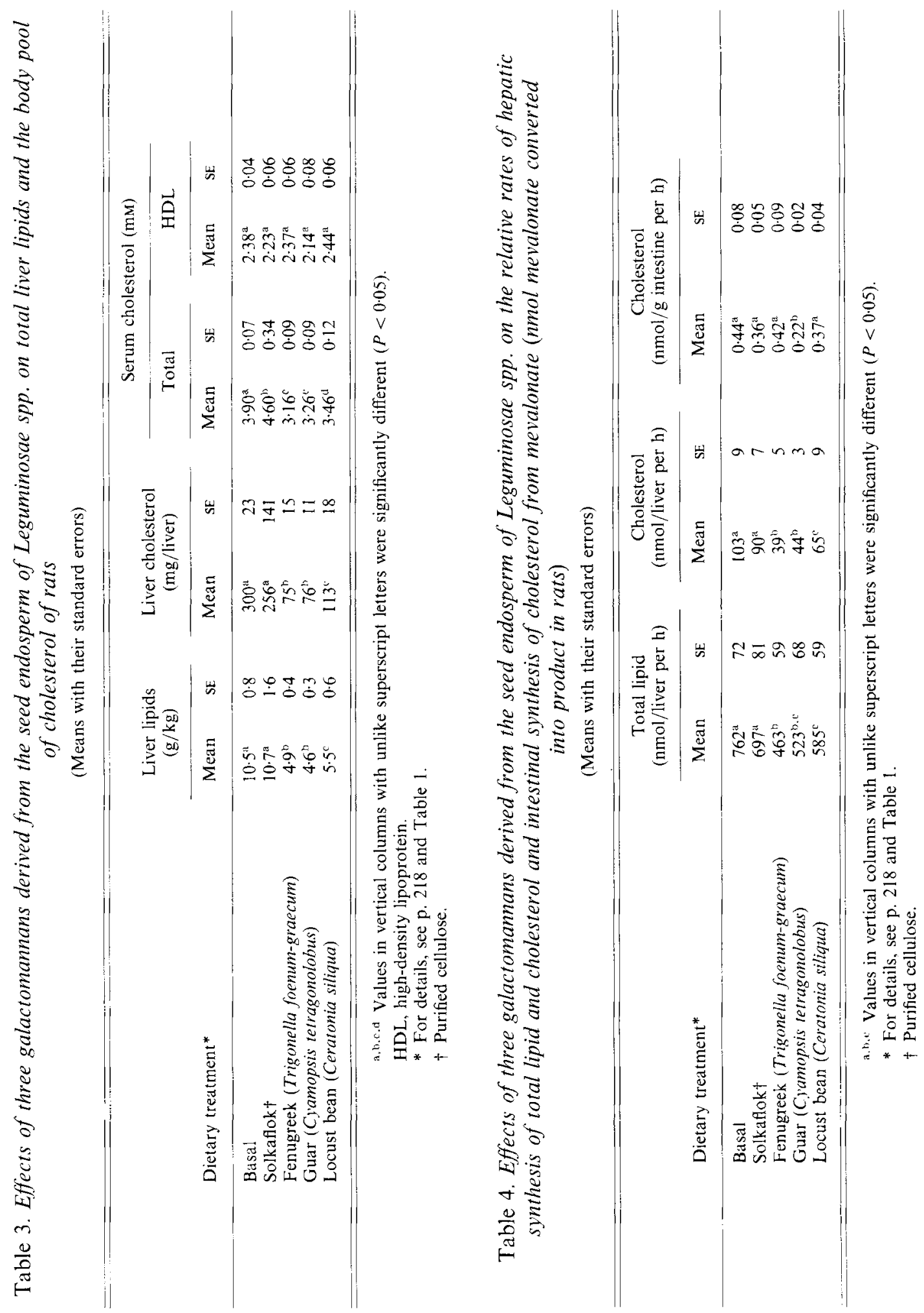


Table 5. Effects of three galactomannans derived from the seed endosperm of Leguminosae spp. on caecal volatile fatty acid concentration of rats

(Means with their standard errors)

\begin{tabular}{|c|c|c|c|c|c|c|}
\hline \multirow[b]{3}{*}{ Dietary treatment* } & \multicolumn{6}{|c|}{ Volatile fatty acids $(\mu \mathrm{mol} / \mathrm{g})$} \\
\hline & \multicolumn{2}{|c|}{ Acetic } & \multicolumn{2}{|c|}{ Propionic } & \multicolumn{2}{|c|}{ Butyric } \\
\hline & Mean & $\mathrm{SE}$ & Mean & $\mathrm{SE}$ & Mean & SE \\
\hline Basal & $66 \cdot 0^{\mathrm{a}}$ & $3 \cdot 8$ & $20 \cdot 8^{a}$ & $1 \cdot 2$ & $3 \cdot 7^{\mathrm{a}}$ & $0 \cdot 2$ \\
\hline Solkaflok $\dagger$ & $45 \cdot 2^{h}$ & $1 \cdot 0$ & $14 \cdot 0^{\mathrm{t}}$ & $0 \cdot 8$ & $4 \cdot 4^{\mathrm{a}}$ & $0 \cdot 7$ \\
\hline Fenugreek (Trigonella foenum-graecum) & $59 \cdot 7^{\mathrm{a}}$ & $2 \cdot 6$ & $49 \cdot 5^{\prime \prime}$ & $2 \cdot 8$ & $\operatorname{tr}$ & \\
\hline Guar (Cyamopsis tetragonolobus) & $52 \cdot 8^{1)}$ & $3 \cdot 4$ & $57 \cdot 2^{11}$ & 1.4 & $\mathrm{tr}$ & \\
\hline Locust bean (Ceratonia siliqua) & $50 \cdot 5^{\mathrm{b}}$ & $2 \cdot 7$ & $67.9^{\mathrm{e}}$ & $2 \cdot 3$ & $\operatorname{tr}$ & \\
\hline
\end{tabular}

\section{Metabolic correlations}

Correlation coefficients were calculated for pairs of biochemical measurements using the pooled data from the three galactomannan treatment groups. Galactomannans in the diet caused a reduction in caecal $\mathrm{pH}$ (Table 2 ) which was significantly correlated $(P<0.01)$ with the increase in propionic acid production, but not with acetic acid production (Table 6). Plasma cholesterol and the rate of hepatic cholesterol synthesis were significantly correlated $(P<0.01)$; however, neither of these two quantities were related to caecal propionate production.

\section{Viscosity}

The viscosities of aqueous solutions of the three galactomannans were compared at two different concentrations ( 5 and $10 \mathrm{~g} / \mathrm{kg}$ ) and over a broad range of rates of shear. The results are shown in Fig. 3. The solutions are non-newtonian and all three curves show the decrease in apparent viscosity with increasing shear rate typical of food gums (Bourne, 1982). Contrary to a previous report (Bourne, 1982) we were unable to detect a yield stress at low shear rates for any of the samples.

More relevant to the present study, the results presented in Fig. 3 show the relative viscosities of the three galactomannans at shear rates within the range encountered during passage of digesta through the small intestine. Taking the radius of the rat small intestine to be approximately $3 \mathrm{~mm}$ and the maximum flow-rate for the digesta to be $2 \mathrm{ml} / \mathrm{min}$., the shear rate ranges from zero at the centre to approximately $2 / \mathrm{s}$ at the wall (Sherman, 1970). Within this range the results show that guar gum is the most viscous and fenugreek gum the least viscous of the three galactomannans.

The results presented are comparative among treatment groups for the perfused intestine which behaves like a tube of constant radius with a steady flow; in our experiments, $2 \mathrm{ml} / \mathrm{min}$. However, in vivo, due to waves of contractions migrating along the length of the intestine, the diameter of the gut wall will vary. Intermittent stirring and changing peristaltic pressures may result in shear rates at the point of maximum constriction that are higher than the theoretical values quoted in Fig. 3. 


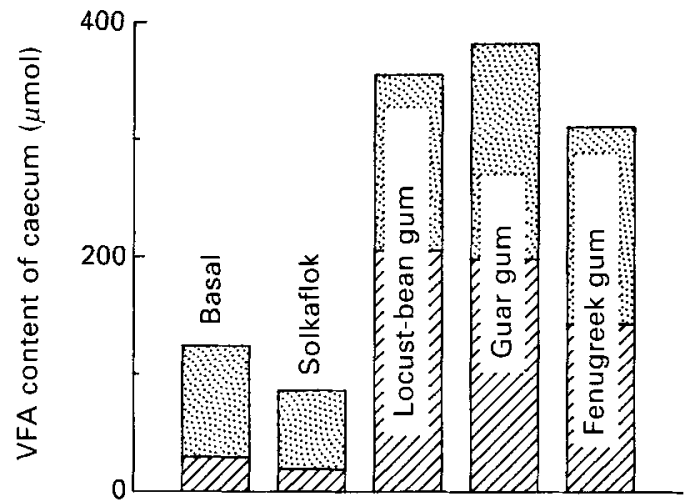

Fig. 2. Effect of dietary galactomannans derived from the seed endosperm of Leguminosae spp. on the caecal content of acetic (圆) and propionic (B) acids ( $\mu \mathrm{mol} / \mathrm{caecum})$ in rats. VFA, volatile fatty acids. Solkaflok (purified cellulose), locust bean (Ceratonia siliqua), fenugreek (Trigonella foenum-graecum) and guar (Cyamopsis tetragonolobus) gum were included at $80 \mathrm{~g} / \mathrm{kg}$ diet. For details of diets, see p. 218 and Table 1.

Table 6. Selected correlation coefficients for biochemical measurements in rats from the three groups fed on galactomannans derived from the seed endosperm of Leguminosae spp.

(Correlation coefficients numerically greater than 0.56 are significant $(P<0.01)$

\begin{tabular}{lr} 
Comparison & Correlation coefficient \\
Caecal pH v. caecal propionate & -0.79 \\
Caecal pH v. caccal acetate & -0.38 \\
Plasma cholesterol v. cholesterol synthesis & 0.61 \\
Plasma cholesterol v. caecal propionate & 0.26 \\
Cholesterol synthesis $v$. caecal propionate & 0.25 \\
\hline
\end{tabular}

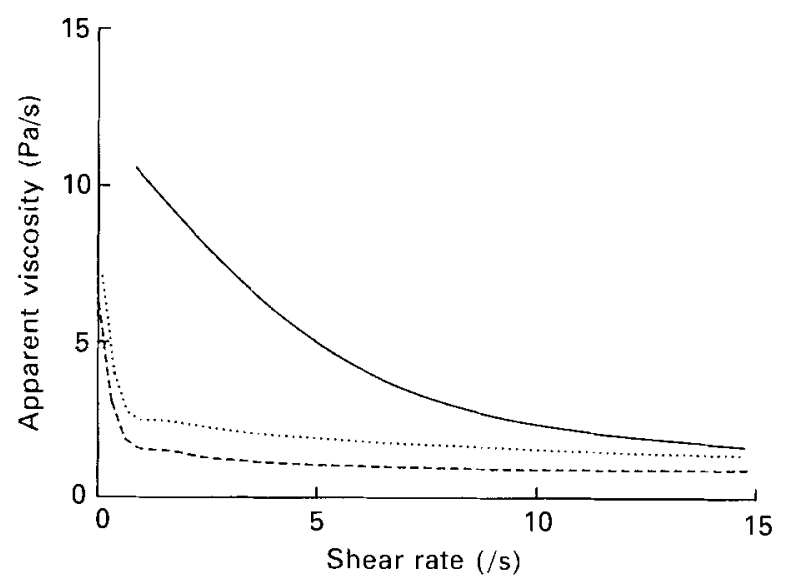

Fig. 3. Apparent viscosity $v$. shear rate for guar (Cyamopsis tetragonolobus) gum (-), locust bean (Ceratonia siliqua) gum (...) and fenugreek (Trigonella foenum-graecurn) gum (--) at a concentration of $10 \mathrm{~g} / \mathrm{kg}$. Rates of shear within the rat small intestine would be approximately within the range zero to $2 / \mathrm{s}$.

\section{Effect of fenugreek gum on cholesterol absorption from the small intestine in vivo}

In a separate study, isotonic solutions containing fenugreek gum and cholesterol were circulated through loops of small intestine in vivo in the rat. Fenugreek gum had no significant effect on the rate of absorption of cholesterol, as shown in Table 7 . It also had 
no effect on the rate of absorption of taurocholate but there was a small, but statistically significant, inhibition of absorption of glucose in both the upper and lower loops.

\section{DISCUSSION}

\section{Influence of chemical structure on cholesterol-lowering activity}

The ability of guar gum to lower plasma and liver cholesterol concentrations is now well established (Jenkins et al. 1975, 1980; Simons et al. 1982). Locust-bean gum has also been shown to lower plasma cholesterol (Zavoral et al. 1983) as have fenugreek seeds (but not the isolated gum; Sharma 1986). So the powerful cholesterol-lowering activity of the three galactomannans in the present study is not in itself unexpected. What is of interest is that the magnitude of the effect is influenced by subtle changes in the chemical structure of the galactomannan.

The galactomannans all have the same $\beta$-D-mannan backbone. They differ only in the proportion of D-galactosyl side groups per D-mannose residue, as shown in Fig. 1. Guar gum, for example, has approximately twice as many D-galactosyl side groups per Dmannose as locust-bean gum (Dea \& Morrison, 1975). The side groups appear to be arranged along the backbone in blocks rather than randomly, but this fine structure is not well defined. Studies with locust-bean gum have indicated batch-to-batch variations, possibly resulting from different extraction and purification procedures (Dea \& Morrison, 1975).

The results presented in Tables 2 and 3 suggest that the cholesterol-lowering activity of the galactomannans depends on the D-galactose: D-mannose ratio. The greater this ratio, the greater the activity. This effect appears to be perfectly consistent for different variables. Thus, the magnitude of the lowering of total plasma cholesterol was in the order: fenugreek $>$ guar gum $>$ locust-bean gum (Table 2); the magnitude of suppression of hepatic cholesterol synthesis was in the same order (Table 3 ).

\section{The mechanism of cholesterol-lowering by galactomannans}

Do these results shed any light on the mechanism of cholesterol-lowering by galactomannans? Three possible mechanisms currently seem plausible:

(1) Soluble fibre increases the viscosity of the digesta and this may inhibit the absorption of cholesterol from the small intestine and also the reabsorption of bile acids from the terminal ileum (Gee et al. 1983).

(2) Soluble fibre is an excellent substrate for the micro-organisms in the large bowel. The fermentation that takes place there produces volatile fatty acids (Smith \& Bryant, 1979) which enter the blood stream and may influence hepatic synthesis of cholesterol (Ide et al. 1978; Anderson \& Bridges, 1981).

(3) Fibre may adsorb bile acids in the small intestine (Eastwood \& Hamilton, 1968; Kritchevsky \& Story, 1974). Adsorbed bile acids would be diverted from the enterohepatic cycle, lost by faecal excretion, and this loss offset by conversion of cholesterol into bile acids by the liver (Heaton, 1972).

Our results argue against the first of these suggestions. Viscosity does not seem to be a significant factor. The magnitude of the cholesterol-lowering effect of the three galactomannans was in the opposite order to their effect on viscosity. The most viscous (guar) had less effect on plasma cholesterol than the least viscous (fenugreek). Also, in the separate study of the effect of fenugreek gum on absorption from perfused loops of small intestine, the gum had no significant effect on the rate of absorption of cholesterol (Table 7). The gum did, however, significantly inhibit the absorption of glucose.

These results are supported by the findings of Topping et al. (1988) who compared the 


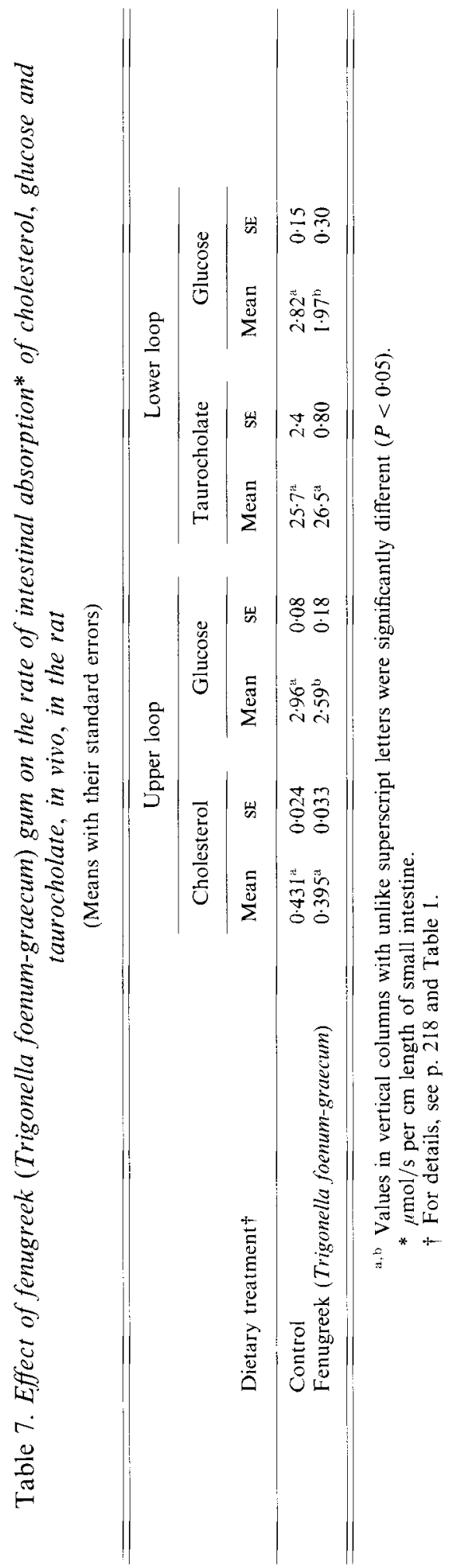


effects in the rat of feeding methyl celluloses of different grades of viscosity. In their experiments also, viscosity had no influence on plasma cholesterol concentrations, but did influence plasma glucose. Moreover, gum acacia has no significant effect on viscosity yet produced a $10.4 \%$ reduction in plasma cholesterol when included in the diet of a group of hypercholesterolaemic men (Sharma, 1985).

Our results are also inconsistent with the second proposed mechanism. The cholesterollowering activity of the galactomannans appears not to be directly related to their susceptibility to fermentation in the large bowel. The galactomannan with the greatest cholesterol-lowering activity had least effect on caecal $\mathrm{pH}$ and least effect on the size of the caecum and mass of caecal contents (Table 2). But, at the same time, the three galactomannans did produce substantial reductions in the rate of hepatic synthesis of cholesterol. Moreover, the magnitude of the reduction was in each case proportional to the lowering of plasma cholesterol.

Another point to be considered in this connexion is that the concentration of propionate which was found to inhibit cholesterol synthesis in vitro was ten to fifteen times higher than that actually found in the portal vein in vivo during fermentation of soluble fibre in the large bowel (Illman et al. 1988). Although propionic acid production was significantly correlated with caecal $\mathrm{pH}$ in rats fed on galactomannan, it was not related to plasma cholesterol concentration or to the rate of hepatic synthesis of cholesterol. Consequently the effects of soluble fibre on plasma cholesterol appear not to be related to propionate production. Cheng et al. (1987) also reported no relationship between individual volatile fatty acids and either blood glucose or plasma lipids.

The third mechanism, that of adsorption of bile acids, is supported by the finding that, in the rat, cholesterol-lowering by oat bran is accompanied by increased faecal excretion of bile acids (Illman \& Topping, 1985). However, our gut perfusion study (Table 7) showed that there was no effect from fenugreek gum on intestinal absorption of taurocholate. Moreover, cholesterol-lowering by pectin is also accompanied by increased faecal excretion of bile acids (Kay \& Truswell, 1977) but adsorption of bile acids onto pectin appears to be physically impossible at gut $\mathrm{pH}$ because both molecules are negatively charged (Oakenfull \& Sidhu, 1984). Pectin at concentrations up to $30 \mathrm{~g} / \mathrm{l}$ did not affect the rate of cholate diffusion through cellulose membranes (Oakenfull \& Sidhu, 1984). This concentration is not likely to be exceeded in the digesta of human subjects ingesting soluble dietary fibres. Judd \& Truswell (1982) did not find any significant differences in plasma cholesterol or faecal steroid excretion in human subjects fed on either low- or high-methoxyl pectins. The degree of hydrophobicity of these pectins would strongly influence any capacity they might have to absorb bile acids. Thus, intestinal absorption and binding of bile acids or cholesterol by soluble fibres does not satisfactorily explain their hypocholesterolaemic effect.

Thus, our results are not wholly consistent with any of the possible mechanisms so far proposed to explain how soluble fibre influences cholesterol metabolism. It may be relevant that rats fed on guar gum or carboxymethylcellulose (another soluble fibre) show significant adaptive differences when compared with animals fed on similar quantities of insoluble cellulose (Johnson \& Gee, 1986). There were substantial morphological changes in the large bowel and changes in the activities of some brush-border enzymes. This is confirmed in part in our study which showed large increases in the size of the caecum in response to feeding the galactomannans. Also, again as observed in our study, Johnson \& Gee (1986) found significant quantitative differences between the effects of their two types of soluble fibre. In another study, using mice (Stanley \& Newsholme 1985), guar gum was shown to increase the activity of a number of key enzymes in carbohydrate and lipid metabolism by the liver, despite the fact that the guar gum remains in the gastrointestinal tract. The link may possibly be via the gastrointestinal hormones since guar gum reduces 
the secretion of gastric inhibitory polypeptide and gut glucagon-like immunoreactivity in human subjects (Morgan et al. 1979).

Thus, the mechanism by which soluble fibre lowers plasma cholesterol is complex and remains poorly understood.

The authors thank Mr David Everett (Dairy Research Laboratory, CSIRO Division of Food Processing) for his assistance with the viscosity measurements and Ms Linda Stephens (CSIRO Biometrics Unit) for assistance with statistical analyses.

\section{REFERENCES}

Anderson, J. W. \& Bridges, S. R. (1981). Plant fiber metabolites alter hepatic glucose and lipid metabolism. Diabetes 30, Suppl. 1, 133A.

Behal, K. M., Lee, K. H. \& Moser, P. B. (1984). Blood lipids and lipoproteins in adult men fed four refined fibers. American Journal of Clinical Nutrition 39, 209-214.

Bligh, E. G. \& Dyer, W. J. (1959). A rapid method of tolal lipid extraction and purification. Canadian Journal of Biochemistry and Physiology 37, 911917

Bourne, M. B. (1982). Food Texture and Rheology: Concept and Measurement. New York: Academic Press.

Chen, W. J. L.. Anderson, J. W. \& Gould, M. R. (1981). Effects of oat bran, oat gum and pectin on lipid metabolism of cholesterol-fed rats. Nutrition Reports Inteinational 24, 1093-1098.

Cheng, B. Q., Trimble, R. P., Illman, R. J., Stone, B. A. \& Topping, D. L. (1987). Comparative effects of dietary wheat bran and its morphological components (aleurone and pericarp-seed coat) on volatile fatty acid concentrations in the rat. British Journal of Nutrition 57,69-81.

Dea, I. C. M. \& Morrison, A. (1975). Chemistry and interactions of seed galactomannans. Advances in Carbohydrate Chemistry and Biochemistry 31, 241312.

Eastwood, M. A. \& Hamilton, D. (1968). Studies on the adsorption of bile salts to non-absorbed components of diet. Biochinica et Biophysica Acta 152, 165173.

Gee, J. M., Blackburn, N. A. \& Johnson, I. T. (1983). The influence of guar gum on intestinal cholesterol transport in the rat. British Journal of Nutrition 50, $215 \% 224$.

Heaton, K. W. (1972). Bile Salts in Health and Disease. Edinburgh: Churchill-Livingstone.

Hood. R. L. (1987). A note on the cholesterol content of beef rib steaks. CSIRO Food Resemeh Quarterly 47. 44-46.

Hood, R. L. (1990). Effect of diet and substrate on the in vitro measurement of cholesterol and fatty acid synthesis in hepatic tissue of Japanese quail (Coturnix coturnix japonica). Poultry Science 69, 647-652.

Ide, T. Okamastu, H. \& Sugano, M. (1978). Regulation of dietary fats of 3-hydroxy-3-methylglutaryl-coenzyme A reductase in rat liver. Journal of Nutrition 108, 601-607.

Illman, R. J. \& Topping, D. L. (1985). Effects of dietary oat bran on faecal steroid excretion, plasma volatile fatty acids and lipid synthesis in rats. Nutrition Research 5,839\%846.

Illman, R. J., Topping, D. L., Mclntosh, G. H., Trimble, R. P., Storer, G. B., Taylor, M. N. \& Cheng. B. Q. (1988). Hypocholesterolaemic effects of dietary propionate studies in whole animals and perfused rat liver. Annals of Nutrition and Metabolism 32.97106.

Jenkins, D. J. A., Leeds, A. R., Newton, C. \& Cummings, J. H. (1975). The effect of pectin, guar gum and wheat fibre on serum cholesterol. Lance' i, 11161117.

Jenkins. D. J. A., Reynolds, D., Slavin, B., Leeds. A. R., Jenkins, A. L. \& Jepson, E. H. (1980). Dietary fiber and blood lipids: treatment of hypercholesterolemia with guar crispbread. American Journal of Clinical Nutrition 33. 575581 .

Johnson. I. T. \& Gee, J.M. (1986). Gastrointestinal adaptation in response to soluble non-available polysaccharides in the rat. British Journal of Nutrition $\mathbf{5 5}, 497 \ldots 505$.

Judd, P. A. \& Truswell, A. S. (1982). Comparison of effects of high-and low-methoxyl pectins on blood and faecal lipids in man. British Journal of Nutrition 48, 451458.

Judd, P. A. \& Truswell, A. S. (1985). The hypocholesterolaemic elfects of pectins in rats. British Journal of Nutrition 53, 409-425.

Kay, R. M. \& Truswell, A. S. (1977). Effect of citrus pectin on blood lipids and faecal sterol excretion in man. American Jounal of Clinical Nutrition 30, 171176.

Kirby, R. W.. Anderson, J. W. \& Sieling, B. (1981). Oat-bran intake selectively lowers serum low-density lipoprotein cholesterol concentrations of hypercholesterolemic men. American Journal of Clinical Nutrition $\mathbf{3 4}$, $824 \cdot 829$.

Kritchevsky, D. \& Story, J. A. (1974). Binding of bile salls in vitro by non-nutritive fiber. Journal of Nutrition 104. $458 \cdots 462$.

Morgan. L. M., Goulder. T. J., Tsioladis, D., Marks, V. A. \& Alberti, K. G. M. M. (1979). The effeet of unabsorbable carbohydrate on gut hormones. Modification of postprandial GIP secretion by guar. Diabetologia 17, 85-89. 
Oakenfult, D. G. (1988). Oat bran-Does oat bran lower plasma cholesterol... and if so. how? CSIRO Food Research Quarterly 48, 37-39.

Oakenfull, D. G. \& Sidhu, G. S. (1984). Effects of pectins on intestinal absorption of glucose and cholate in the rat. Nutrition Reports International 30, 1269-1278.

Osilesi, O., Trout, D. L., Glover, E. E., Harper, S. M., Koh, E. T., Behal, K. M., O’Dorisio, T. M. \& Tartt, J. (1985). Use of xanthan gum in dietary management of diabetes mellitus. American Journal of Clinical Nutrition 42, 597603 .

Rudel, L. L. \& Morris, M. D. (1973). Determination of cholesterol using o-phthalaldehyde. Journat of Lipid Research 14, 364366.

Sharma, R. D. (1985). Hypocholesterolemic effect of gum acacia in men. Nutrition Research 5, 1321-1326.

Sharma. R. D. (1986). Effect of fenugreek seeds and leaves on blood glucose and serum insulin response in human subjects. Nutrition Research 6, 13531364.

Sherman, P. (1970). Industrial Rheology. London: Academic Press.

Simons, L. A., Gayst, S., Balasubramaniam, S. \& Ruys, J. (1982). Long-term treatment of hypercholesterolaemia by a new palatable formulation of guar gum. Atherosclerosis 45, 101-109.

Smith, C. J. \& Bryant, M. P. (1979) Introduction of metabolic activities of intestinal bacteria. American Journal of Clinical Nutrition 32, 149-163.

Snedecor, G. W. \& Cochran, W. G. (1989), Statistical Methods, 8th ed., p. 177. Ames: Iowa State University Press.

Stanley, J. C. \& Newsholme, E. A. (1985). The effects of dietary guar gum on the activities of some key enzymes of carbohydrate and lipid metabolism in mouse liver. British Journal of Nutrition 53, 215-222.

Topping, D. L., Oakenfull, D., Trimble, R. P. \& Illman. R. J. (1988). A viscous fibre (methyl cellulose) lowers blood glucose and piasma triacylglycerols and increases liver glycogen independently of volatile fatty acid production in the rat. British Joumal of Nutrition 59, 21-30.

Zavoral, J. H., Hannon, P., Fields, D. J., Hanson, M. N., Frantz, I. D., Kuba, K., Elmer, P. \& Jacobs, D. R. (1983). The hypolipidemic effect of locust bean gum in familial hypercholesterolemic adults and children. American Journal of Climicat Nutrition 38, 285-294. 